\title{
A Mathematical Programming Model for Optimal Layout Considering Quantitative Risk Analysis
}

\author{
Nancy Medina-Herrera ${ }^{1}$, Arturo Jiménez-Gutiérrez ${ }^{1 *}$ and Ignacio E. Grossmann ${ }^{2}$ \\ ${ }^{1}$ Instituto Tecnológico de Celaya, Departamento de Ingeniería Química, Celaya, Gto 38010 México \\ ${ }^{2}$ Carnegie Mellon University, Chemical Engineering Department, Pittsburgh, PA 15213 USA
}

Keywords: Optimization; Mixed-Integer Programming; Safety; Quantitative risk analysis; Plant layout

*Corresponding author. Phone: +52-461-611-7575 Ext. 5577. E-mail: arturo@iqcelaya.itc.mx

\begin{abstract}
Safety and performance are important factors in the design and operation of chemical plants. This paper describes the formulation of a mixed integer nonlinear programming model for the optimization of plant layout with safety considerations. The model considers a quantitative risk analysis to take safety into account, and a bowtie analysis is used to identify possible catastrophic outcomes. These effects are quantified through consequence analyses and probit models. The model allows the location of facilities at any available point, an advantage over grid-based models. Two case studies are solved to show the applicability of the proposed approach.
\end{abstract}

\section{Introduction}

Chemical plants must not only be cost effective, but also avoid or minimize the risk of major hazards, which places safety as one of the major components in the operation of chemical plants. History supports this fact. The Texas City refinery explosion in 2005 and the Flixborough disaster in 1974, among others, are examples of lack of safety in chemical plants due to poor layouts and back-up systems. Facility siting and layout is an important item in risk management and safety (Crowl \& Louvar, 2002). A good facility siting and a proper layout contribute to an inherently safer plant and better risk management, and may even reduce occupied land and operation costs (Patsiatzis et al., 2004). 
The Center for Chemical Process Safety (CCPS) has published guidelines for facility siting and layout (AIChE, 2003). The CCPS guidelines, based on industry practice and standards, provide guidance for finding an optimal production site and for proper placing of units within the plant. However, the guidelines do not provide a systematic method for plant layout. Mathematical programming has been applied to model layout problems. Georgadis et al. (1999) have proposed a general mathematical programming approach for plant layout under restrictions of fixed safety distances. Penteado and Ciric (1996) developed an MINLP model for safe process layout considering three possible hazardous incidents in an ethylene oxide plant. Addition of safety devices to decrease consequences in case of an incident was also taken into account. Vazquez-Roman et al. (2010) proposed an MINLP model that considers atmospheric uncertainties under toxic releases using Monte Carlo simulation. Jung et al. (2010a) developed a systematic approach for facility layout considering fire and explosion scenarios using a gridbased MILP model. In a second work, Jung et al. (2010b) reported a MINLP model for facility layout considering toxic releases using CFD software to validate the results. These works have particularly contributed to a better understanding and modeling of the relationship between layout and safety. However, most of them have focused on worst-case scenarios, which give only a partial view of the entire spectrum of risk sources, typically overestimating risk.

This work aims at providing a more elaborate analysis of risk sources by considering a complete quantitative risk analysis (QRA). A QRA identifies common scenarios and quantifies their corresponding risk. In this way, a QRA finds possible outcomes, among them the most frequent one, and the scenario with highest consequences. We propose a mathematical model that yields a systematic algorithm for plant layout following CCPS guidelines for facility siting and layout. The proposed model requires a bowtie analysis, which identifies potential catastrophic outcomes given a failure within dangerous process equipment. Once the outcomes are identified, an MINLP model is formulated to find the optimal location for process units and equipment. The objective function considers risk of workers at the units, risk of damage to process equipment, and land and interconnection costs. The objective function is subject to geometry constraints, non-overlapping constraints, scenarios characterization constraints, and consequences quantification constraints considering economic data and wind direction uncertainty.

The outline of the paper is as follows. First, we introduce basic concepts and common risk management procedures. Next, we present the problem statement and state some assumptions for the formulation of the MINLP model. The general formulation of the model is explained and relevant constraints such as geometrical relations, disjunctions for nonoverlapping, frequency analysis, consequences analysis, the objective function, and the reformulation of the disjunctions are addressed in detail. Two examples are then used to show the application of the proposed model. 


\section{Background}

In dealing with safety, a common practice is to relate it with risk. Risk is defined as a function of probability of a loss and the loss itself. In chemical plants such a loss is a consequence of an abnormal event (loss of equipment, injured people, loss of material, etc.) Risk management is the identification, assessment and prioritization of risk. In industry, a well-accepted risk identification method is a hazard and operability study (HAZOP), which is developed through the contributions of experienced people to assess possible failures of equipment and operation. Venkatasubramanian et al. (2003a; 2003b; 2003c) have shown several fault identification methods and discussed their strengths and weaknesses. Qualitative and quantitative assessment can be performed; while a risk matrix is generally the principal method for qualitative assessment ( $\mathrm{Ni}$ et al., 2010), a QRA is a more detailed method because it requires identification of failures, failure rates data, and a consequence analysis. Qualitative methods are simpler and represent a good starting point, while quantitative methods give more specific data and a better prioritization of risk. A disadvantage of a quantitative analysis is that failure rates and environmental conditions are uncertain. Some works have proved the importance of using plant-specific failures rates estimations rather than generic values within chemical plants (Meel \& Seider, 2008; Meel et al., 2008).

In this work, a QRA is considered to optimize the facility layout of the plant. Figure 1 shows a graphical representation of the risk quantification by means of a QRA, which requires the quantification of both frequency and consequences. The probability quantification can be performed using fault trees, which identify the possible failures that cause a release of material, and event trees, which identify the outcomes caused by the released material. Both analyses are combined into one, yielding a bowtie analysis. Therefore, from a bowtie analysis the probability of all outcomes can be quantified based on historic plant-specific data and expert judgment (top part of Figure 1.) After the outcomes are identified by the bow tie analysis, an analysis is performed to quantify the consequences. An outcome consequence analysis includes dispersion models, the characterization of the causative variable (thermal radiation flux, generated overpressure, amount and duration of the release), and the effects quantification using a probit model (bottom part of Figure 1).

\section{Problem statement}

Facility layout is a challenging problem due to its relationship with safety, operational procedures and plant cost, which are often conflicting factors. This work addresses the optimal layout of a chemical plant considering a complete QRA. The resulting MINLP model is based on CCPS guidelines for facility siting and layout alternative methodology. The problem for a specified chemical process can be stated as follows:

Given 
- Most common failures within the process and their failure rates and expert judgment for environmental conditions

- Wind direction probability analysis of the site (wind rose)

- The amount of mass released, flowrate and physical and chemical properties

- A flat land area chosen by a siting analysis with a maximum length $L x$ and depth $L y$

- A set of hazardous units $H$ at fixed location $\left(x_{H}, y_{H}\right)$ and their dimensions in $\mathrm{x}$ axis, $L_{H}$, and y axis, $W_{H}$

- A set of facilities or units $U$ and their dimensions in $x$ axis, $L_{U}$, and y axis, $W_{U}$

- The average number of workers near unit $i, N_{\text {workers }}^{i}$ for $i \in U$

- Economic data on costs for units interconnections, equipment, life prevention, and land

- Average environmental parameters such as humidity, air molecular weight, and similar factors.

Determine

- The set of potential catastrophic events $E$ and their probability of occurrence $P_{E}$

- All units center locations $\left(x_{i}, y_{i}\right)$ for $i \in U$

- Total occupied area $A_{\text {land }}$

- Optimal distances $D_{i, j}$ between units $i \in U$ and dangerous units $j \in H$

- Optimal distances $D u_{i, k}$ between units, $i, k \in U$

- Final cost related to interconnection, equipment damage, workers injured and land

With the goal to minimize the plant layout cost, $P L C$.

The proposed model assumes that geotechnical, atmospheric and topological studies were developed in advance of siting the plant. There are no hills or valleys that effect dispersion of gases, and the superficial land under consideration has the same characteristics. Also, there are no particular advantages for some equipment to be located in a particular site. Natural disasters are not considered based on results of historical data and weather studies. A QRA is developed for the most dangerous processes or units $(H)$, and the identified outcomes are the only risk sources considered. The model assumes that a previous siting analysis has been performed to locate the dangerous units, while the location of the non-dangerous units has to be selected.

\section{Mathematical formulation}


The proposed mixed integer optimization model for the optimal layout problem is described below.

\section{Geometry relations}

The distances between units are defined by Euclidean distances. Therefore, the distance $D_{i, j}$ from the geometrical center of unit $i$ to the geometrical center of dangerous equipment $j$ is the square root of the sum of squares of the horizontal and vertical segments. Likewise, $D u_{i, k}$ is the distance between non-dangerous units $i$ and $k$. The occupied land area, $A_{l a n d}$, is the area defined by the longest segment in the horizontal and vertical directions. The longest segment is the difference between the largest coordinate Side $_{1}$ and the smallest coordinates Side $_{2}$ in both horizontal and vertical directions. The corresponding distances are shown in Equation (1).

$$
\begin{aligned}
& D_{i, j}=\sqrt{\left(x_{i}-x_{j}\right)^{2}+\left(y_{i}-y_{j}\right)^{2}} \quad \forall i \in U, \forall j \in H \\
& D u_{i, k}=\sqrt{\left(x_{i}-x_{k}\right)^{2}+\left(y_{i}-y_{k}\right)^{2}} \quad \forall i, k \in U, i \neq k \\
& \operatorname{Side}_{1}^{x} \geq x_{i}+\frac{L_{i}}{2} \\
& \operatorname{Side}_{2}^{x} \leq x_{i}-\frac{L_{i}}{2} \\
& \operatorname{Side}_{1}^{y} \geq y_{i}+\frac{W_{i}}{2} \\
& \text { Side }_{2}^{y} \leq y_{i}-\frac{W_{i}}{2} \\
& A_{\text {land }}=\left(\operatorname{Side}_{1}^{x}-\operatorname{Side}_{2}^{x}\right) *\left(\operatorname{Side}_{1}^{y}-\operatorname{Side}_{2}^{y}\right)
\end{aligned}
$$

\section{Non-overlapping disjunctions}

In order to ensure non-overlapping between the rectangle areas occupied by each unit, disjunctions for non-overlapping constraints similar to those by Sawaya and Grossmann (2012) are used. The Boolean variables $Z_{i, j}$ represent the four possible relative positions of unit $j$ with respect to unit $i$ (right, left, above and below). The geometrical center $\left(x_{j}, y_{j}\right)$ of unit $j$ must be placed so that its length and height, $L_{j}$ and $H_{j}$, do not overlap with unit $i$, and it can take any of the four possible position (see Equation (2) and Figure 2).

$$
\left[\begin{array}{c}
Z_{i, j}^{R} \\
x_{i}+\frac{L_{i}}{2} \leq x_{j}-\frac{L_{j}}{2}
\end{array}\right] \vee\left[\begin{array}{c}
Z_{i, j}^{L} \\
x_{j}+\frac{L_{j}}{2} \leq x_{i}-\frac{L_{i}}{2}
\end{array}\right] \mathrm{V}\left[\begin{array}{c}
Z_{i, j}^{A} \\
y_{i}+\frac{H_{i}}{2} \leq y_{j}-\frac{H_{j}}{2}
\end{array}\right] \mathrm{V}\left[\begin{array}{c}
Z_{i, j}^{B} \\
y_{j}+\frac{H_{j}}{2} \leq y_{i}-\frac{H_{i}}{2}
\end{array}\right] \quad \forall i, j \in U \cup H, i<j
$$




\section{Quantitative Risk Analysis}

Risk is defined as a function of probability and consequences, which can be a loss of workers' life or equipment (AIChE, 2000). The first one, societal risk for unit $i$ originated in dangerous equipment $\mathrm{j}, R_{\text {societal }}^{i, j}$, is equal to the damage fraction for the sum of all events, $P w_{i, j}^{e} / 100$, times the number of dead workers, $N_{\text {workers, }}^{i}$ times the probability of occurrence of event $e$ originated in dangerous equipment $\mathrm{j}, P_{e}^{j}$, assuming that the population is exposed throughout the total duration of event $e$. The second one, process equipment risk for unit $i, R_{\text {equipment }}^{i, j}$ is a function of the damage to equipment due to incident $e, P e_{i, j}^{e} / 100$, and its probability of occurrence $P_{e}^{j}$. Equation (3) shows both risk definitions.

$$
\left.\begin{array}{c}
R_{\text {societal }}^{i, j}=\sum_{e}^{E} P_{e}^{j} \frac{P w_{i, j}^{e}}{100} N_{\text {workers }}^{i} \\
R_{\text {equipment }}^{i, j}=\sum_{e}^{E} P_{e}^{j} \frac{P e_{i, j}^{e}}{100}
\end{array}\right\} \forall i \in U, \forall j \in H
$$

The quantification of probability of occurrence $P_{e}^{j}$ is performed through a frequency analysis and the quantification of consequences is evaluated with a consequences analysis, both of which are described below.

\section{Frequency Analysis}

Potential outcomes of an abnormal operation are identified by a frequency analysis, which provides the probabilistic part of risk for each of the outcomes. A fault tree is, on the one hand, a visualization tool that shows causes (failures) of a top event (in this case release of hazardous material); on the other hand, an event tree is a visualization tool that helps to identify outcomes due to an initiating event. Bow tie graphs combine fault and event trees to carry out frequency analysis (Modarres et al., 2010). Outcome frequencies are calculated from failures rates and probabilities of events.

The most common failures generating high consequences are here considered, namely: (1) rupture of process equipment, (2) rupture of a liquid pipe, and (3) rupture of a vapor pipe. Such failures can produce two types of releases depending on the rupture size (total or partial). A partial rupture means rupture of less than $20 \%$ of the total diameter, and a total rupture means rupture of $20 \%$ or more. Two types of releases can occur, an instantaneous release produced by a total rupture, and a continuous release caused by a partial rupture. Once material is released, outcomes can be identified depending on probabilities of ignition and atmospheric conditions. Examples of bow tie graphs are shown in Figures 3 and 4. 
In Figure 3 a boiling liquid expanding vapor explosion (BLEVE), an unconfined vapor cloud explosion (UVCE) and flash fire due to instantaneous release (FFI) are identified as outcomes. Probabilities of these are calculated following the outcome path. Frequency of an instantaneous release is equal to the sum of failure rate of catastrophic rupture of dangerous equipment, ffide, and catastrophic leakage from pipes. Failure rate of catastrophic leakage from pipes is equal to the sum of the failure rate ruptures of at least $20 \%$ of medium pipes and large diameter pipes, ffimp and ffilp, times the pipeline length of medium and large size, $\operatorname{lmp}$ and $l l p$. The probability of an immediate ignition, piii, the probability of a delayed ignition, pidi, and the probability of atmospheric conditions favoring UVCE, pifu, are considered as parameters within the mathematical model. The corresponding equations are given in Equation set (4).

$$
\begin{gathered}
P_{B L E V E}^{\text {bowtie }}=\text { piii } *(\text { ffide }+ \text { ffimp } * \operatorname{lm} p+\text { ffilp } * l l p) \\
P_{U V C E}^{\text {bowtie }}=(1-\text { piii }) * \text { pidi } * \text { pifu } *(\text { ffide }+ \text { ffimp } * \operatorname{lm} p+\text { ffilp } * l l p) \\
P_{F F I}^{\text {bowtie }}=(1-\text { piii }) * \text { pidi } *(1-\text { pifu }) *(\text { ffide }+ \text { ffimp } * \operatorname{lmp}+\text { ffilp } * l l p)
\end{gathered}
$$

From Figure 4, jet fire (JF) and flash fire continuous (FFC) events are identified. Frequency of a continuous release is equal to the sum of the failure rates of serious rupture of equipment, $f f c d e$, and serious leakage from pipelines. Failure rate of serious leakage from pipelines is a linear combination of frequency of failure of rupture of at most $20 \%$ of diameter, ffimp and ffilp, and length of pipeline, $\operatorname{lmp}$ and $l l p$, for both medium and large sizes. The probabilities of an immediate ignition, $p c i i$, and delayed ignition, $p c d i$, are also considered as parameters. The corresponding equations are shown in Equation (5).

$$
\begin{gathered}
P_{J F}^{b o w t i e}=p c i i *(f f c d e+f f c m p * l m p+f f c l p * l l p) \\
P_{F F C}^{b o w t i e}=(1-p c i i) * p c d i *(f f c d e+f f c m p * \operatorname{lm} p+f f c l p * l l p)
\end{gathered}
$$

Events originated by a delayed ignition have risk as a function of wind direction and unit location. Therefore, it is important to consider meteorological studies and the wind rose of the particular site (Marx \& Cornwell, 2009). From a bow tie diagram, such wind dependent events are identified. A new subset of outcomes is defined, $W R \in E$, which contains outcomes whose consequences depend on wind direction (delayed ignition). Wind direction is an uncertain phenomenon, and the best approach is to use historical data as a basis. The probability of delayed ignition is equal to one if the released material flows near any unit. In others words, it depends on the wind direction probability. The angle between unit $i$ and the dangerous equipment $j$, angle $e_{i, j}$, is equal to the arctangent of the slope, which is the relation of the difference of coordinates in $\mathrm{x}$ and $\mathrm{y}, \Delta x_{i}^{j} / \Delta y_{i}^{j}$. Next, the wind rose is divided into a set of slices, $S$, defined by a lower and upper fixed angle, $L A_{S}$ and $U A_{S}$, with different probabilities for wind direction, $P f_{s}$. We propose linear constraints for the probability of event e, modeled as a disjunction in Equation (6). The outcome probability, $P_{e}$, is equal to bowtie probability, $P_{e}^{\text {bowtie }}$, 
times the probability of wind direction in the slice, $P f_{S}$. For outcomes not contained in WR, the probability of ocurrence, $P_{e}^{j}$, is equal to bowtie probability, $P_{e}^{\text {bowtie }}$. This formulation is simpler than the proposed by Vazquez et al. (2010), which introduces a zero-one variable matrix to identify the quadrant and leads to convergence problems.

$$
\begin{array}{r}
\text { angle }_{i, j}=\operatorname{atan} 2\left(\Delta x_{i}^{j} / \Delta y_{i}^{j}\right) \\
\Delta x_{i}^{j}=x_{i}-x_{j} \\
\Delta y_{i}^{j}=y_{i}-y_{j} \\
Y_{s} \\
\vee \\
\operatorname{v} \in S\left[\begin{array}{c}
\operatorname{angle}_{i, j} \geq L A_{s} \\
\operatorname{angle}_{i, j} \leq U A_{s} \\
P_{e}^{j}=P_{e}^{\text {bowtie }} * P f_{s}
\end{array}\right] \\
P_{e}^{j}=P_{e}^{\text {bowtie }} \quad \forall e \in E \mid e \notin W R, \forall i \in U, \forall j \in W R
\end{array}
$$

\section{Consequence Analysis}

Consequence analysis provides quantified effects of each outcome in bow tie graphs. Dispersion, outcome characteristic variable and effects calculations are included in the mathematical model. BLEVE, UVCE, FFI, JF and FFC are the five possible events (AIChE, 2000).

\section{Consequence Quantification}

A Probit model is used to calculate the outcome effects. Probit methods provide a generalized time dependent function, which can be used for toxic, thermal and blast effects. The probit variable of event $e$ originated in dangerous equipment $j$ and received by unit $i, Y_{i, j}^{e}$, is a function of a causative variable logarithm, $\ln V_{i, j}^{e}$, and two adjustable constants, $k_{1}^{e}$ and $k_{2}^{e}$. Probit variables, $Y_{i, j}^{e}$, can be converted to percentage of damage, $P d_{i, j}^{e}$. The general percentage of damage, $P d_{i, j}^{e}$, is used indistinctly for $P w_{i, j}^{e}$ and $P e_{i, j}^{e}$. The first one refers to percentage of affected workers, and the second one to damaged equipment. The probit model is shown in equation (7), with adjustable constants given in tables 1, 2 and 3 for every type of event and causative variable. Each event has a different causative variable, $V_{i, j}^{e}$.

$$
\begin{gathered}
Y_{i, j}^{e}=k_{1}^{e}+k_{2}^{e} \ln V_{i, j}^{e} \\
\left.P d_{i, j}^{e}=50\left[1+\frac{Y_{i, j}^{e}-5}{\left|Y_{i, j}^{e}-5\right|} \operatorname{erf}\left(\frac{\left|Y_{i, j}^{e}-5\right|}{\sqrt{2}}\right)\right]\right\} \quad \forall i \in U, \forall j \in H, \forall e \in E
\end{gathered}
$$




\section{Characterization of non-wind direction dependent events}

\section{BLEVE}

A BLEVE has two principal hazards, projectiles and thermal radiation. Projectiles damage, important because of its domino effects, is not considered in this analysis. Equation (8) shows a BLEVE characterization modeled by empirical and radiation equations.

$$
\begin{aligned}
& D_{\max }=5.8 Q^{*^{1 / 3}} \\
& t_{B L E V E}=0.45 Q^{*^{1} / 3} \text { for } Q^{*}<30000 \mathrm{Kg} \\
& t_{B L E V E}=2.6 Q^{* 1 / 6} \text { for } Q^{*}>30000 \mathrm{Kg} \\
& H_{B L E V E}=0.75 D_{\max } \\
& P_{w}=1013.25(R H) \exp \left(14.4114-\frac{5328}{T_{a}}\right) \\
& X s_{i, j}^{B L E V E}=\sqrt{D_{i, j}^{2}+H_{B L E V E}^{2}}-\frac{D_{\max }}{2} \\
& \tau_{i, j}^{B L E V E}=2.02\left(P_{w} X s_{i, j}^{B L E V E}\right)^{-0.09} \\
& {\left[\begin{array}{c}
Z_{i, j}^{B L E V E} \\
D_{i, j} \geq \frac{D_{\max }^{j}}{2} \\
F_{i, j}^{B L E V E}=\frac{D_{i, j}\left(D_{\max }^{j} / 2\right)^{2}}{\left(D_{i, j}^{2}+\left(H_{B L E V E}^{j}\right)^{2}\right)^{1.5}}
\end{array}\right] \vee\left[\begin{array}{c}
\neg Z_{i, j}^{B L E V E} \\
D_{i, j}<\frac{D_{\max }^{j}}{2} \\
F_{i, j}^{B L E V E}=\frac{H_{B L E V E}^{j}\left(D_{\max }^{j} / 2\right)^{2}}{\left(D_{i, j}^{2}+\left(H_{B L E V E}^{j}\right)^{2}\right)^{1.5}}
\end{array}\right]} \\
& E_{\text {BLEVE }}=\frac{R * Q^{*} H_{c o m b}}{\pi D_{\text {max }}^{2} t_{B L E V E}} \\
& E r_{i, j}^{B L E V E}=\tau_{i, j}^{B L E V E} E_{B L E V E} F_{i, j}^{B L E V E} \\
& Y_{i, j}^{B L E V E}=k_{1}^{B L E V E}+k_{2}^{B L E V E} \ln V_{i, j}^{B L E V E} \\
& P d_{i, j}^{B L E V E}=50\left[1+\frac{Y_{i, j}^{B L E V E}-5}{\left|Y_{i, j}^{B L E V E}-5\right|} \operatorname{erf}\left(\frac{\left|Y_{i, j}^{B L E V E}-5\right|}{\sqrt{2}}\right)\right]
\end{aligned}
$$

The causative variable thermal radiation, $E r_{i, j}$, is a function of the atmospheric transmissivity, $\tau_{i, j}^{B L E V E}$, the view factor, $F_{i, j}^{B L E V E}$, and thermal emissive power, $E_{B L E V E}$. These variables are related to distance between the fireball surface and the receptor, $X s_{i, j}^{B L E V E}$, and receptorsource distance, $D_{i, j}$. The parameters are the mass released, $Q^{*}$, material heat of combustion, $H_{c o m b}$, maximum fireball's diameter, $D_{\text {max }}$, duration, $t_{B L E V E}$, and fireball height, $H_{B L E V E}^{j}$. The expression for partial pressure, $P_{w}$, is a function of relative humidity, $R H$, and air temperature, $T_{a}$, as given by Mudan and Croce (1988). Hymes (1983) suggested a combustion heat radiation fraction, $R$, from 0.3 to 0.4 . In this analysis, $R$ is taken as 0.4 for a conservative estimate. The model for view factor, $F_{i, j}^{B L E V E}$, presents a discontinuity, which is formulated here as a 
disjunction. The BLEVE causative variables, $V_{i, j}^{B L E V E}$, and probit constants for workers' life loss and equipment damage are reported in tables 1, 2 and 3.

Jet fire

A jet fire (JF) is produced by the combustion of a pressurized vessel leak. In general, jet fire consequences are considered important only in neighboring areas. As in the BLEVE model, thermal radiation hazard is the main causative variable of this event. Thermal radiation, $E r_{i, j}^{J F}$, is a function of discharge rate, $\dot{m}_{r}$, flame size, $L_{\text {flame }}$, fraction of total energy converted to radiation, $\eta_{J F}$, heat of combustion, $\mathrm{H}_{\text {comb }}$, point view factor, $F_{i, j}^{J F}$, atmospheric transmissivity, $\tau_{i, j}^{J F}$, and indirectly of distance of receptor-source, $D_{i, j}$, and distance from flame center to receptor, $X s_{i, j}^{J F}$. Flame size is a function of molecular weight of air, $M_{a}$, molecular weight of fuel, $M_{f}$, jet diameter, $d_{j}$, and the fuel mole fraction concentration in a stoichiometric fuel-air mixture, $C_{T}$, see Equation (9). Tables 1,2 and 3 show the JF probit variables, $V_{i, j}^{J F}$, for workers' life loss and equipment damage.

$$
\begin{aligned}
& \frac{L_{\text {flame }}}{d_{j}}=\frac{15}{C_{T}} \sqrt{\frac{M_{a}}{M_{f}}} \\
& X s_{i, j}^{J F}=\sqrt{D_{i, j}^{2}+L_{\text {flame }}^{2}} \\
& P_{w}=1013.25(R H) \exp \left(14.4114-\frac{5328}{T_{a}}\right) \\
& \tau_{i, j}^{J F}=2.02\left(P_{w} X s_{i, j}^{J F}\right)^{-0.09} \\
& F_{i, j}^{J F}=\frac{1}{4 \pi D_{i, j}^{2}} \\
& E r_{i, j}^{J F}=\tau_{i, j}^{J F} \eta_{J F} \dot{m}_{r} \mathrm{H}_{\mathrm{comb}} F_{i, j}^{J F} \\
& Y_{i, j}^{J F}=k_{1}^{J F}+k_{2}^{J F} \ln V_{i, j}^{J F} \\
& \left.P d_{i, j}^{J F}=50\left[1+\frac{Y_{i, j}^{J F}-5}{\left|Y_{i, j}^{J F}-5\right|} \operatorname{erf}\left(\frac{\left|Y_{i, j}^{J F}-5\right|}{\sqrt{2}}\right)\right]\right)
\end{aligned}
$$

\section{Wind direction-dependent scenarios}

From bow tie diagrams, scenarios with a delayed ignition are identified. The consequences of such scenarios depend on wind direction and location of ignition sources. In this work, safe distance, $D_{\text {safe }}^{j}$, is defined as the distance where the released material cannot be ignited. A mixture is flammable if it has a concentration between upper and lower flammability limits (UFL-LFL.) Thus, the safety distance is given by the position where concentration in air is lower 
than the LFL value. Figure 5 illustrates a material release from dangerous unit $\mathrm{j}$ and its unsafe area defined by the largest circle at a concentration equal to LFL. Therefore, ignition can happen in unit $i$ or unit $k$ but not in unit $m$ because unit $m$ is located out of the reach of a flammable mixture.

Wind direction-dependent events require dispersion calculations. Several dispersion models have been proposed (AIChE, 2000; Crowl \& Louvar, 2002; Mannan et al., 2005). The dispersion model used in this analysis is the one by Pasquill-Gifford (Gifford, 1982), a simple model that assumes passive dispersion. There are two types of releases with different dispersion phenomena depending on the amount of released material by unit time. We specify the atmospheric conditions, rural conditions and class F stability (very stable), as worst-case conditions.

Equation (10) represents a ground level instantaneous release dispersion model. The average concentration due to instantaneous release, $\left\langle C_{i}\right\rangle$, is a function of the mass released, $Q^{*}$, the dispersion coefficients in downwind, crosswind and axial directions $\left(\sigma_{x}, \sigma_{y}\right.$ and $\left.\sigma_{z}\right)$, wind velocity, $u$, time, $t$, and position, $(x, y, z)$.

$$
\left.\begin{array}{c}
\left.<C_{i}>(x, 0,0, t)=\frac{Q^{*}}{\sqrt{2}(\pi)^{1.5} \sigma_{x} \sigma_{y} \sigma_{z}} \exp \left\{-\frac{1}{2}\left[\left(\frac{x-u t}{\sigma_{x}}\right)^{2}+\frac{y^{2}}{\sigma_{y}^{2}}+\frac{z^{2}}{\sigma_{z}^{2}}\right]\right\}\right) \\
\sigma_{x}=0.024 * x^{0.89} \\
\sigma_{y}=0.024 * x^{0.89} \\
\sigma_{z}=0.05 * x^{0.61}
\end{array}\right\}
$$

Equation (11) models the dispersion for a point ground level continuous release. The average concentration due to continuous release, $\left\langle C_{c}\right\rangle$, is a function of the leaking flowrate, $\dot{m}_{r}$, the dispersion coefficients in downwind, crosswind and axial directions $\left(\sigma_{x}, \sigma_{y}\right.$ and $\left.\sigma_{z}\right)$, wind velocity, $u$, and position, $(x, y, z)$. Both instantaneous and continuous dispersion models were taken from Crowl and Louvar (2002).

$$
\left.\begin{array}{rl}
<C_{c}>(x, y, z) & \left.=\frac{\dot{m}_{r}}{\pi \sigma_{y} \sigma_{z} u} \exp \left\{-\frac{1}{2}\left[\frac{y^{2}}{\sigma_{y}{ }^{2}}+\frac{z^{2}}{\sigma_{z}{ }^{2}}\right]\right\}\right) \\
\sigma_{y} & =\frac{0.04 x}{\sqrt{1+0.0001 x}} \\
\sigma_{z} & =\frac{0.016 x}{1+0.0003 x}
\end{array}\right\}
$$

Values for safe distances are calculated for instantaneous and continuous releases solving equations (10) and (11), respectively, considering a downwind location $(x, 0,0)$ and using a concentration equal to LFL. Then, the safe distance value is obtained, $D_{\text {safe }}^{j}=x$, and the unsafe 
area is a circle defined by a radius equal to $D_{\text {safe }}^{j}$ and center at the dangerous unit j location. This model assumes that each unit has ignition sources. Consequently, the probability of ignition depends on wind direction and unit location. The models to characterize consequences from wind-dependent events are described below.

UVCE

UVCE is an explosion originated by a release that allows the formation of a cloud that finds an ignition source and gets fired. In Figure 5 for example, a cloud can be ignited in unit I and unit $k$ but not in unit $\mathrm{m}$. Hence, there are no consequences for unit $\mathrm{m}$. However, there are possible consequences for units $\mathrm{i}$ and $\mathrm{k}$. If the cloud gets ignited in unit $\mathrm{l}$, the resulting overpressure affects units $\mathrm{k}$ and $\mathrm{m}$, Equation (12). A disjunction is proposed to model the consequences, whose occurrence depends on wind direction. The Boolean variable, $Z_{i, j}^{U V C E}$, is true if the distance between unit $i$ and dangerous unit $j, D_{i, j}$, is less than the safe distance for an instantaneous release, $D i_{s a f e}^{j}$, and the total damage percentage originated from unit $i, P d_{i, j}^{U V C E}$, is the sum of partial losses in the other units $P p_{i, k, j}^{U V C E}$ and in the same unit $P p_{i, i, j}^{U V C E}$. If $Z_{i, j}^{U V C E}$ is false, then there are no consequences from UVCE ignited in unit i. The consequences of ignition in unit $i$ is the sum of the damage produced to the others units. For that reason, we formulated a partial probit model that quantifies effects on the other units. Then, a partial probit variable, $Y_{i, k, j}^{U V C E}$, and a partial percentage of damage, $P p_{i, k, j}^{U V C E}$, originated by a release in unit $j$, ignited in unit $i$ and received by unit $k$ are used. Tables 1,2 and 3 show the UVCE causative variables, $V_{i, k, j}^{U V C E}$, and constants for workers' life loss and equipment damage risk. The main hazard of a UVCE is the overpressure, $p^{o}{ }_{i, k}$, originated at location of unit $i$ and received by unit $k$. The overpressure $p_{i, k}^{o}$ is a function of the mass released, $Q^{*}$, fuel heat of combustion, $H_{c o m b}$, and receptor-source distance, $D u_{i, k}$. A TNT equivalence model used in this analysis is based on a comparison between the mass and heat of combustion of released material, $Q^{*} H_{c o m b}$, and mass and combustion heat of TNT, $W H_{T N T}$, considering an efficiency explosion factor, $\eta_{U V C E} ; a, b$ and $c$ are constants related to TNT explosions. 


$$
\begin{aligned}
& W=\frac{\eta_{U V C E} Q^{*} H_{c o m b}}{H_{T N T}} \\
& Z m_{i, k}=\frac{D u_{i, k}}{W^{1 / 3}} \\
& \log _{10}\left(p_{i, k}^{o}\right)=\sum_{i=0}^{12} c_{i}\left(a+b \log _{10} Z m_{i, k}\right)^{i} \\
& a=-0.2144 \\
& b=1.3503 \\
& c_{i}=[2.7808,-1.6959,-0.1542,0.5141,0.0989,-0.2939 \text {, } \\
& 0.0268,0.1091,0.0016,-0.0215,0.0001,0.0017] \\
& Y_{i, k, j}^{U V C E}=k_{1}^{U V C E}+k_{2}^{U V C E} \ln V_{i, k, j}^{U V C E} \\
& P p_{i, k, j}^{U V C E}=50\left[1+\frac{Y_{i, k, j}^{U V C E}-5}{\left|Y_{i, k, j}^{U V C E}-5\right|} \operatorname{erf}\left(\frac{\left|Y_{i, k, j}^{U V C E}-5\right|}{\sqrt{2}}\right)\right] \\
& P p_{i, i, j}^{U V C E}=100 \\
& {\left[\begin{array}{c}
Z_{i, j}^{U V C E} \\
D_{i, j} \leq D i_{\text {safe }}^{j} \\
P d_{i, j}^{U V C E}=\sum_{k}^{U} P p_{i, k, j}^{U V C E}
\end{array}\right] \vee\left[\begin{array}{c}
\neg Z_{i, j}^{U V C E} \\
D_{i, j}>D i_{\text {safe }}^{j} \\
P d_{i, j}^{U V C E}=0
\end{array}\right]} \\
& \forall i, k \in U, \forall j \in H
\end{aligned}
$$

\section{FFC and FFI}

A flash fire due to a continuous (FFC) or an instantaneous (FFI) release is caused by a flammable mixture of liquid and vapor that ignites. A flash fire is a complex event that does not behave as liquid or as vapor; it lacks a well-accepted characterization model due to the complexity of the occurring physical phenomena. Consequently, the distance of impact is considered as the distance at LFL concentration, and everything inside LFL is considered as a total loss (Rew et al., 1996). Concentration of LFL for instantaneous and continuous releases is calculated with equations (10) and (11), respectively. A disjunction is used to assign percentage of damage to workers and equipment, $P w_{i, j}^{e}$ and $P e_{i, j}^{e}$, Equation (13).

$$
\left[\begin{array}{c}
Z_{i, j}^{e} \\
D_{i, j} \leq D_{\text {safe }} \\
P w_{i, j}^{e}=100 \\
P e_{i, j}^{e}=100
\end{array}\right] \vee\left[\begin{array}{c}
\neg Z_{i, j}^{e} \\
D_{i, j}>D_{\text {safe }} \\
P w_{i, j}^{e}=0 \\
P e_{i, j}^{e}=0
\end{array}\right] \forall i \in U, \forall j \in H, e \in F F I, F F C
$$

\section{Disjunction Reformulation}

The models for non-overlapping, wind direction, BLEVE, UVCE, FFC and FFI (Equations (2), (6), (8), (12) and (13)) involve disjunctions. We reformulate the problem using convex hull for 
disjunctions that contain linear constraints, and the Big-M method for Equation (8), a non-linear constraint.

The reformulation of non-overlapping disjunctions, Equation (2), is given below in terms of the disaggregated variables $x_{i, d}$ and $y_{i, d}$,

$$
\left.\begin{array}{c}
x_{i}=\sum_{d}^{D} x_{i, d} \\
y_{i}=\sum_{d}^{D} y_{i, d} \\
x_{i, 1}-x_{j, 1} \leq-\left(\frac{L_{i}}{2}+\frac{L_{j}}{2}\right) z_{i, j, 1}^{n o} \\
x_{j, 2}-x_{i, 2} \leq-\left(\frac{L_{i}}{2}+\frac{L_{j}}{2}\right) z_{i, j, 2}^{n o} \\
y_{i, 3}-y_{j, 3} \leq-\left(\frac{H_{i}}{2}+\frac{H_{j}}{2}\right) z_{i, j, 3}^{n o} \\
y_{j, 4}-y_{i, 4} \leq-\left(\frac{H_{i}}{2}+\frac{H_{j}}{2}\right) z_{i, j, 4}^{n o} \\
\sum_{d}^{D} z_{i, j, d}^{n o}=1 \\
0 \leq x_{i, d} \leq U x_{i} * z_{i, j, d}^{n o} \\
0 \leq y_{i, d} \leq U y_{i} * z_{i, j, d}^{n o}
\end{array}\right\} \forall i, j \in U \cup H, i<j
$$

The wind rose disjunction within Equation (6) is transformed into:

$$
\begin{aligned}
& \text { angle }_{i, j}=\sum_{S}^{S} \text { angle }_{i, j, s} \\
& P_{e}^{j}=\sum_{s}^{S} P_{e, s}^{j} \\
& \text { angle }_{i, j, s} \geq L A_{s} z_{s}^{w r} \\
& \text { angle }_{i, j, s} \leq U A_{s} z_{S}^{w r} \\
& P_{e, s}^{j}=P_{e}^{\text {bowtie }} P f_{s} z_{S}^{w r} \\
& \sum_{s}^{S} z_{S}^{w r}=1 \\
& \left.\begin{array}{c}
\text { Langle }_{i, j} z_{s}^{w r} \leq \text { angle }_{i, j, s} \leq \text { Uangle }_{i, j} * z_{s}^{w r} \\
0 \leq P_{e, s}^{j} \leq U P_{e}^{j} z_{s}^{w r}
\end{array}\right)
\end{aligned}
$$

The disjunction within the UVCE model becomes, 


$$
\left.\begin{array}{c}
D_{i, j}=\sum_{l=1}^{2} D_{i, j, l} \\
P p_{i, k, j}^{U V C E}=\sum_{l=1}^{2} P p_{i, k, j, l}^{U V C E} \\
P d_{i, k, j}^{U V C E}=\sum_{l=1}^{2} P d_{i, j, l}^{U V C E} \\
D_{i, j, 1} \leq D i_{s a f e}^{j} * z_{i, j, 1}^{U V C E} \\
P d_{i, j, 1}^{U V C E}=\sum_{k}^{U} P p_{i, k, j, 1}^{U V C E} * z_{i, j, 1}^{U V C E} \\
D_{i, j, 2}>D_{s a f e} * z_{i, j, 2}^{U V C E} \\
P d_{i, j, 2}^{U V C E}=0 \\
0 \leq D_{i, j, l} \leq U D_{i, j} z_{i, j, l}^{U V C E} \\
0 \leq P p_{i, k, j, l}^{U V C E} \leq U P p_{i, k, j}^{U V C E} z_{i, j, l}^{U V C E} \\
0 \leq P d_{i, j, l}^{U V C E} \leq U P d_{i, j}^{U V C E m a x} z_{i, j, l}^{U V C E}
\end{array}\right\} \quad \forall i, k \in U, i<k, \forall j \in H
$$

The disjunction for consequences for FFC and FFI effects is reformulated as,

$$
\left.\begin{array}{c}
D_{i, j}=\sum_{k=1}^{2} D_{i, j, k} \\
P w_{i, j}^{e}=\sum_{k=1}^{2} P w_{i, j, k}^{e} \\
P e_{i, j}^{e}=\sum_{k=1}^{2} P e_{i, j, k}^{e} \\
D_{i, j, 1} \leq D_{s a f e} * z_{i, j, 1}^{e} \\
P w_{i, j, 1}^{e}=100 * z_{i, j, 1}^{e} \\
P e_{i, j, 1}^{e}=100 * z_{i, j, 1}^{e} \\
D_{i, j, 2}>D_{s a f e} * z_{i, j, 1}^{e} \\
P w_{i, j, 2}^{e}=0 \\
P e_{i, j, 2}^{e}=0 \\
\sum_{k=1}^{2} z_{i, j, k}^{e}=1 \\
0 \leq D_{i, j, k} \leq U D_{i, j} z_{i, j, k}^{e} \\
0 \leq P w_{i, j, k}^{e} \leq U P w_{i, j}^{e} z_{i, j, k}^{e} \\
0 \leq P e_{i, j, k}^{e} \leq U P e_{i, j}^{e} z_{i, j, k}^{e}
\end{array}\right\} \forall i \in U, \forall j \in H, e \in F F I, F F C
$$

For the BLEVE scenario, a Big-M model is used, 


$$
\left.\begin{array}{c}
D_{i, j} \geq \frac{D_{\max }^{j}-M\left(1-z_{i, j, 1}^{B L E V E}\right)}{2}-D_{i, j}\left(D_{\max }^{j} / 2\right)^{2} \\
F_{i, j}^{B L E V E}>M\left(1-z_{i, j, 1}^{B L E V E}\right) \\
F_{i, j}^{B L E V E}<\frac{D_{i, j}\left(D_{\max }^{j} / 2\right)^{2}}{\left(D_{i, j}^{2}+\left(H_{B L E V E}^{j}\right)^{2}\right.}+M\left(1-z_{i, j, 1}^{B L E V E}\right) \\
F_{i, j}^{B L E V E}>\frac{H_{B L E V E}^{j}\left(D_{\max }^{j} / 2\right)^{2}}{\left(D_{i, j}^{2}+\left(H_{B L E V E}^{j}\right)^{2}\right)^{1.5}}-M\left(1-z_{i, j, 2}^{B L E V E}\right) \\
F_{i, j}^{B L E V E}<\frac{D_{B L E V E}^{j}\left(D_{\max }^{j} / 2\right)^{2}}{\left(D_{i, j}^{2}+\left(H_{B L E V E}^{j}\right)^{2}\right)^{1.5}}+M\left(1-z_{i, j, 2}^{B L E V E}\right)
\end{array}\right\} \quad \forall i \in U, \forall j \in H
$$

\section{Objective function}

The objective function is the minimization of the Plant Layout Cost, $P L C$, which includes the effects of societal risk and equipment risk, plus the units distance of interconnection times interconnection costs, and land cost times occupied area:

$$
P L C=\sum_{j}^{H}\left(\sum_{i}^{U} R_{\text {societal }}^{i, j} * C_{\text {prev }} * L_{\text {proj }}+\sum_{i}^{U} R_{\text {equipment }}^{i, j} * C_{\text {equipment }}^{i} * L_{\text {proj }}+\sum_{i}^{U} D_{i, j} * C_{\text {con }}^{i, j}\right)+C_{\text {land }} A_{\text {land }}
$$

The mixed-integer non linear optimization model consists in the minimization of the objective function Equation (19) subject to the geometry relations Equation (1), the reformulation of nonoverlapping disjunction Equation (14), the risk definitions Equation (3), the frequency analysis Equations (4) and (5), the wind rose Equation (6) and its reformulation Equation (15), the BLEVE consequences model Equation (8) and the reformulation Equation (18), JF consequences model Equation (9), UVCE consequences model Equation (12) and its convex hull disjunction reformulation Equation (16), and finally FFI and FFC consequences models Equation (13) and reformulation Equation (17). The model was solved using DICOPT with the GAMS software environment (Brooke et al., 2006) 


\section{Case studies}

Two case studies are presented. The first case study was adapted from the CPQRA example reported in the CCPS Guidelines (AIChE, 2000). A hydrocarbon separation unit of $n$-hexane/nheptane is considered as the dangerous unit due to a large amount of flammable material. $A$ flat area of $250 \mathrm{~m}$ in the east direction and $500 \mathrm{~m}$ in the north direction is considered. Land cost is equal to $\$ 6 / \mathrm{m}^{2}$. The separation unit is located in the middle, at point $(125,250)$. In addition to the separation unit, a small storage atmospheric tank, an office building and the main control room need to be located. General parameters for the units are given in Table 4, including dimensions, people near unit, equipment and interconnection costs.

CCPS guidelines report that the mass of $\mathrm{n}$-hexane released is equal to $28,000 \mathrm{Kg}$ for an instantaneous release, and a flow of $11 \mathrm{Kg} / \mathrm{s}$ for a continuous release. For dispersion calculations, a wind velocity of $1.5 \mathrm{~m} / \mathrm{s}$ is taken as a worst-case scenario to provide conservative results. Figure 6 shows the wind rose provided for the site in the CCPS book; the 360 degrees were divided into eight slices, with boundaries shown in Table 5 . In addition, there are restrictions for safety distances between units considered in the model. Table 6 shows reported values for common industry safety distances (AIChE, 2003).

Bowtie graphs were developed based on the fault and event trees reported in the CCPS book, and the results are shown in Figures 3 and 4; there are five possible events for this case, BLEVE, UVCE, FFI, JF and FFC. For the bow tie analysis, failure rates and expert judgment probabilities were taken from the Rijnmond area report (COVO Committee, 1982) and the CCPS book, with a length of $25 \mathrm{~m}$ for large pipeline and $55 \mathrm{~m}$ for medium pipeline. As part of the model solution, the outcomes can be categorized by their probabilities of occurrence as given in Table 7. Jet fire is the most probable event and a vapor cloud explosion and flash fire due to an instantaneous release are the least probable.

In addition, the CCPS book reports that UVCE and BLEVE present the largest death rate. In general, the worst-case scenario is considered as either the most probable or the highest consequences scenario. Some approaches consider the highest consequences scenario for conservative results. However, without a QRA it is difficult to define which scenario is the most probable and which one has the worst consequences. In this work the layout optimization was performed considering all catastrophic outcomes as identified from a bowtie analysis. The MINLP model for this problem involves 123 0-1 variables, 536 continuous variables and 1234 constraints, and the solution took $7.83 \mathrm{sec}$ of CPU time with DICOPT.

The resulting layout is presented in Figure 7. The fixed location for the distillation unit DU (dangerous unit) is $(125,250)$. All units meet safety distances criteria. Center locations for units 1,2 and 3 are $(145,325.69),(130,485)$, and $(120,439.92)$. The objective function value was 
$\$ 116,406$, considering a project life of 5 years. The final occupied area $A_{\text {land }}$, yellow rectangle, is equal to $10,600 \mathrm{~m}^{2}$, distributed in $40 \mathrm{~m}$ in the east direction and $265 \mathrm{~m}$ in the north direction. As expected, Unit 1, small storage, is the closest unit to the dangerous equipment due to the interconnection penalty. Unit 2, Office, is the most distant from the dangerous equipment due to the number of people therein. The final layout locates all units in a low wind direction probability.

The model was also solved considering outcomes individually. In Figure 8, individual objective function values for each outcome are shown, together with the total objective function (PLC). A jet fire is the most common incident, but it has the smallest footprint. Therefore, the layout obtained considering only jet fire has the largest PLC, because it shows the lowest consequences from all of the other events, and as a result the risk is underestimated. On the other hand, UVCE shows the largest contour impact, and its layout does not yield the most conservative results. Indeed, only the BLEVE scenario provides a conservative result in terms of safety.

Figure 9 (a) shows the cost contribution to the objective function. The BLEVE layout has the lowest societal risk cost, which means that it provides the safest layout solution. However, the solution considering all outcomes has the lowest PLC value. An important aspect to consider is the contributing factors to the objective function. The weight on the objective function of equipment risk cost and interconnection is not as important as land cost and societal risk cost for all cases. The occupied area and societal risk are variables in conflict within the objective function. Such conflict was analyzed varying the land cost parameter within the optimization and monitoring both societal risk and occupied area. The resulting Pareto front is given in Figure $9($ b). The societal risk varies from $9 / 1000$ to $20 / 1000$ dead workers. The weight factors, land cost and cost of prevention of life loss, have an important impact in the layout results.

The results from this test demonstrate that considering individual worst-case scenario provides a more expensive layout than a simultaneous consideration.

\section{Case Study 2}

This case study is an extension of case study 1 and it was taken from Jung et al. (2010a) These authors used a grid-based model to generate their solution. There are six units to be located, a main control room, an office, an auxiliary building for maintenance, two small atmospheric tanks and a utilities facility, along with two dangerous units, a distillation unit (DU) and a large storage tank (LST). Table 8 describes the general parameters for this case. The properties of distillation unit (DU) are the same as in Example 1 but with different dimensions, $20 \times 20 \mathrm{~m}$. The

other dangerous unit, LST, contains $33,000 \mathrm{Kg}$ of $\mathrm{n}$-hexane to be considered for an instantaneous release, and can provide a flow rate of $6 \mathrm{Kg} / \mathrm{s}$ in the case of a continuous release. 
An available flat area of $250 \times 250 \mathrm{~m}^{2}$ is considered. DU is located at coordinates $(125,125)$ and LST at $(110,130)$. All units are connected with the distillation unit but not with the storage tank (hence cost of LST interconnection is zero). The land cost is $\$ 6 / \mathrm{m}^{2}$.

Table 9 shows reported values for common industry safety distances (AIChE, 2003). These restrictions are included within the model as lower limits for distances between units.

The bow tie graphs for DU and LST are considered the same as in Example 1, see Figures 3 and 4. Thus, the total number of scenarios is ten, BLEVE, UVCE, FFI, JF and FFC for each dangerous unit. As mentioned above, identifying the worst-case scenario becomes a non-trivial task when the number of dangerous units increases. Failures rates for LST are considered equal to those for DU, see Table 7. Figure 6 shows the wind rose provided for the site in the CCPS book; the 360 degrees were divided into five slices, with boundaries shown in Table 10 . The corresponding MINLP model involved 264 binary variables, 1704 continuous variables and 3766 constraints, and was solved in 63.2 sec using DICOPT.

Figure 10 shows the optimal layout predicted by the proposed model, with a cost of $\$ 125651$. This result includes the Euclidean safety distances constraints that the solution from the model by Jung et al. (2010a) cannot handle. It should be pointed out that we used their solution as an initial point, but it was infeasible for our model because the distance between Unit 2, Office, and the LST is lower than the safety Euclidean distance specified here. The problem is that Jung et al. used Manhattan distances in order to generate a linear model, and seemingly did not recalculate the corresponding Euclidean distances to check for feasibility. In our case, Euclidean distances are used, which contributes to the nonlinearities of the model in exchange for a better precision. As expected, the U2 Office is the farthest unit from the dangerous units LST and DU. The six optimal units coordinates are: main control room $(207.4,156.1)$, office $(245$, 79.9), maintenance building $(217.4,156.1)$, small tank $1(121.1,156.1)$, small tank $2(155.9,130)$ and utilities facility $(152.5,140)$. The total occupied area is equal to $13628.85 \mathrm{~m}^{2}$ $(145 \mathrm{~m} \times 86.19 \mathrm{~m})$.

\section{Conclusions}

A new MINLP model for an optimal layout considering a quantitative risk analysis has been proposed. The model can be formulated with fixed facilities (already installed) and/or new facilities. A systematic approach has been used for the integration of economics considerations and uncertain risk scenarios within the optimization procedure. A risk analysis considering flammable material releases is included. A wind rose analysis for the site was considered within the model. Instead of using a predetermined worst-case scenario, a bowtie analysis is developed for each dangerous unit. It was shown that such an approach provides an improvement over models based on worst-case scenarios. Also, the model allows allocating 
units at any available space and evaluates that location convenience within the objective function, which provides a noticeable advantage over grid-based models.

\section{Acknowledgements}

N. Medina-Herrera was supported for a seven-month stay at Carnegie Mellon University as part of the mixed-scholarship program from the National Science for Science and Technology (CONACYT), Mexico.

\section{References}

AIChE (2003). Guidelines for Facility Siting and Layout. Center for Chemical Process Safety/AIChE, New York, NY. AIChE (2000). Guidelines for Chemical Process Quantitative Risk Analysis. 2 ed., AIChE, New York, New York, $\mathrm{p} 756$.

Brooke, A., Kendrick, D., Meeruas, A., \& Raman, R. (2006). GAMS-language guide. Washington, DC: GAMS Development Corporation

COVO Committee (1982). Risk Analysis of Six Potentially Hazardous Objects in the Rijnmond Area, a Pilot Study. D. Reidel Publishing Company, Dorderecht, Holland.

Crowl, D.A., \& Louvar, J. F. (2002). Chemical Process Safety Fundamentals with Applications. Second ed.; Prentice Hall International Series.

Georgiadis, M. C., Schilling, G., Rotstein, G. E., \& Macchietto, S. (1999). A general mathematical programming approach for process plant layout. Computers \& Chemical Engineering, 23 (7), 823-840.

Gifford, F. A. (1982). Horizontal diffusion in the atmosphere: A Lagrangian-dynamical theory. Atmospheric Environment (1967), 16 (3), 505-512.

Hymes, I. (1983). The physiological and pathological effects of thermal radiation, SRD R275. Office, H. S., Ed. London.

Jung, S., Ng, D., Laird, C. D., \& Mannan, M. S. (2010). A new approach for facility siting using mapping risks on a plant grid area and optimization. Journal of Loss Prevention in the Process Industries, 23 (6), 824-830.

Jung, S., Ng, D., Lee, J.-H., Vazquez-Roman, R., \& Mannan, M. S. (2010). An approach for risk reduction (methodology) based on optimizing the facility layout and siting in toxic gas release scenarios. Journal of Loss Prevention in the Process Industries, 23 (1), 139-148.

Landucci, G., Gubinelli, G., Antonioni, G., \& Cozzani, V. (2009). The assessment of the damage probability of storage tanks in domino events triggered by fire. Accident Analysis \& Prevention, 41 (6), 1206-1215.

Mannan, S., Lees, F. P., \& Knovel (Firm). (2005). Lees' loss prevention in the process industries hazard identification, assessment, and control. 3rd ed., Elsevier Butterworth-Heinemann: Amsterdam, Boston. http://www.knovel.com/knovel2/Toc.jsp?BookID=1470. 
Marx, J. D., \& Cornwell, J. B. (2009). The importance of weather variations in a quantitative risk analysis. Journal of Loss Prevention in the Process Industries, 22 (6), 803-808.

Meel, A., \& Seider, W. D. (2008). Real-time risk analysis of safety systems. Computers \& Chemical Engineering, 32 (4-5), 827-840.

Meel, A., Seider, W. D., \& Oktem, U. (2008). Analysis of management actions, human behavior, and process reliability in chemical plants. II. Near-miss management system selection. Process Safety Progress, 27 (2), 139-144.

Mingguang, Z., \& Juncheng, J. (2008). An improved probit method for assessment of domino effect to chemical process equipment caused by overpressure. Journal of Hazardous Materials, 158 (2-3), 280-286.

Modarres, M., Kaminskiy, M., \& Krivtsov, V. (2010). Reliability engineering and risk analysis : $A$ practical guide. 2nd ed., CRC Press: Boca Raton.

Mudan, K. S., \& Croce, P.A. (1988). Fire Hazard Calculations for Large Open Hydrocarbon Fires. Nation Fire Protection Association, Quincy, MA.

Ni, H., Chen, A., \& Chen, N. (2010). Some extensions on risk matrix approach. Safety Science, 48 (10), 1269-1278.

Patsiatzis, D. I., Knight, G., \& Papageorgiou, L. G. (2004). An MILP Approach to Safe Process

Plant Layout. Chemical Engineering Research and Design, 82 (5), 579-586.

Penteado, F. D., \& Ciric, A. R. (1996). An MINLP Approach for Safe Process Plant Layout. Industrial \& Engineering Chemistry Research, 35 (4), 1354-1361.

Rew, P.J., Deaves, D.M., Hockey, S.M., \& and Lines, I.G.. (1996). Review of Flash Fire Modelling. HSE Contract Research Report No. 94/1996.

Sawaya, N., \& Grossmann, I.E. (2012). A hierarchy of relaxations for linear generalized disjunctive programming. European Journal of Operational Research, 216 (1), 70-82.

Vázquez-Román, R., Lee, J.-H., Jung, S., \& Mannan, M. S. (2010). Optimal facility layout under toxic release in process facilities: A stochastic approach. Computers \& Chemical Engineering, 34 (1), 122-133.

Venkatasubramanian, V., Rengaswamy, R., Yin, K., \& Kavuri, S. N. (2003a). A review of process fault detection and diagnosis: Part I: Quantitative model-based methods. Computers \& Chemical Engineering, 27 (3), 293-311.

Venkatasubramanian, V., Rengaswamy, R., \& Kavuri, S. N. (2003b). A review of process fault detection and diagnosis: Part II: Qualitative models and search strategies. Computers \& Chemical Engineering, 27 (3), 313-326.

Venkatasubramanian, V., Rengaswamy, R., Kavuri, S. N., \& Yin, K. (2003c). A review of process fault detection and diagnosis: Part III: Process history based methods. Computers \& Chemical Engineering, 27 (3), 327-346. 
Table 1 Probit model parameters for loss of workers' life $\left(\boldsymbol{P} \boldsymbol{w}_{\boldsymbol{i}, \boldsymbol{j}}^{\boldsymbol{e}}\right)$

\begin{tabular}{cccc}
\hline Event (e) & $\boldsymbol{k}_{\mathbf{1}}^{\boldsymbol{e}}$ & $\boldsymbol{k}_{\mathbf{2}}^{\boldsymbol{e}}$ & $\boldsymbol{V}_{\boldsymbol{i}, \boldsymbol{j}}^{\boldsymbol{e}}$ \\
\hline $\begin{array}{c}\text { Thermal Radiation* } \\
\text { (BLEVE, JET FIRE) }\end{array}$ & -14.9 & 2.56 & $\left(\frac{t_{e} *\left(E r_{i, j}^{e}\right)^{4 / 3}}{10^{4}}\right)$ \\
$\begin{array}{c}\text { Overpressure* } \\
\text { (UVCE) }\end{array}$ & -77.1 & 6.91 & $p^{o}{ }_{i, k}$ \\
\hline *Source: AIChE (2000) & & &
\end{tabular}

Table 2 Probit model parameters for damage to atmospheric equipment $\left(\boldsymbol{P} \boldsymbol{e}_{\boldsymbol{i}, \boldsymbol{j}}^{\boldsymbol{e}}\right)$

\begin{tabular}{cccc}
\hline Event (e) & $\boldsymbol{k}_{\mathbf{1}}$ & $\boldsymbol{k}_{\mathbf{2}}$ & $\boldsymbol{V}$ \\
\hline $\begin{array}{c}\text { Thermal Radiation* } \\
\text { (BLEVE, JET FIRE) }\end{array}$ & 9.25 & -1.85 & $\begin{array}{c}\text { (ttf } / 60) \\
\text { Where }:\end{array}$ \\
& & & $\begin{array}{c}\ln (t t f)=-1.13 \ln \left(E r_{i, j}^{e}\right)-2.67 \times 10^{-5} \text { Vol } \\
+9.9\end{array}$ \\
$\begin{array}{c}\text { Overpressure** } \\
\text { (UVCE) }\end{array}$ & -9.36 & 1.43 & $p^{o}{ }_{i, k}$ \\
\hline
\end{tabular}

*Source: Landucci et al. (2009)

**Source: Mingguang \& Juncheng (2008)

Table 3 Probit model parameters for damage to pressurized equipment $\left(\boldsymbol{P} \boldsymbol{e}_{\boldsymbol{i}, \boldsymbol{j}}^{\boldsymbol{e}}\right)$

\begin{tabular}{cccc}
\hline Event (e) & $\boldsymbol{k}_{\mathbf{1}}$ & $\boldsymbol{k}_{\mathbf{2}}$ & $\boldsymbol{V}$ \\
\hline $\begin{array}{c}\text { Thermal Radiation* } \\
\text { (BLEVE, JET FIRE) }\end{array}$ & 9.25 & -1.85 & $\begin{array}{c}(t t f / 60) \\
\text { Where: }\end{array}$ \\
$\begin{array}{c}\text { Overpressure** } \\
\text { (UVCE) }\end{array}$ & -14.44 & 1.82 & $\ln (t t f)=-0.95 \ln \left(\mathrm{Er}_{i, j}^{e}\right)+8.845 \mathrm{Vol}^{0.032}$ \\
\hline
\end{tabular}

*Source: Landucci et al. (2009)

**Source: Mingguang \& Juncheng (2008) 
Table 4 General parameters for units

\begin{tabular}{lcccc}
\hline \multicolumn{1}{c}{ Unit } & $\begin{array}{c}\text { Dimension } \\
x \times y(\mathrm{~m})\end{array}$ & $\begin{array}{c}\text { People } \\
\text { Nearby }\end{array}$ & $\begin{array}{c}\text { Cost of unit or } \\
\text { equipment }(\$)\end{array}$ & $\begin{array}{c}\text { Cost of } \\
\text { interconnection } \\
(\$ / \mathrm{m})\end{array}$ \\
\hline $\begin{array}{l}\text { Distillation unit } \\
\text { (dangerous unit) }\end{array}$ & $30 \times 30$ & 0 & -- & -- \\
$\begin{array}{l}\text { 1. Small storage } \\
\text { atmospheric tank }\end{array}$ & $10 \times 10$ & 1 & 100000 & 100 \\
2. Office & $40 \times 30$ & 200 & 300000 & 0.1 \\
3. Main control room & $20 \times 10$ & 10 & 1000000 & 10 \\
\hline
\end{tabular}

Table 1 Slice boundaries

\begin{tabular}{cccc}
\hline Slice & $\begin{array}{c}\text { LAs } \\
\text { (degrees) }\end{array}$ & $\begin{array}{c}\text { UAs } \\
\text { (degrees) }\end{array}$ & $\boldsymbol{P f}_{\boldsymbol{s}}$ \\
\hline 1 & 0 & 45 & 0.1 \\
2 & 45 & 90 & 0.1 \\
3 & 90 & 135 & 0.1 \\
4 & 135 & 180 & 0.1 \\
5 & 180 & 225 & 0.15 \\
6 & 225 & 270 & 0.2 \\
7 & 270 & 315 & 0.15 \\
8 & 315 & 360 & 0.1 \\
\hline
\end{tabular}

Table 2 Safety distances

\begin{tabular}{cc}
\hline Units & Small Storage \\
\hline Main control room & $30 \mathrm{~m}$ \\
Office & $15 \mathrm{~m}$ \\
\hline
\end{tabular}


Table 7 Outcomes bowtie probability of occurrence

\begin{tabular}{cccccc}
\hline Outcome & JF & FFC & BLEVE & UVCE & FFI \\
\hline $\mathbf{P}_{\mathbf{e}}^{\mathbf{D U}}$ & $3.67 \times 10^{-5}$ & $2.47 \times 10^{-5}$ & $5.75 \times 10^{-6}$ & $7.76 \times 10^{-7}$ & $7.76 \times 10^{-7}$ \\
\hline
\end{tabular}

Table 8 General parameters for case study 2

\begin{tabular}{ccccc}
\hline Unit & Dimension & $\begin{array}{c}\text { People } \\
\text { Nearby }\end{array}$ & $\begin{array}{c}\text { Equipment } \\
\text { Cost }(\$)\end{array}$ & $\begin{array}{c}\text { Interconnection } \\
(\$ / \mathrm{m})\end{array}$ \\
\hline U1. Main control & $10 \times 10$ & 10 & 1000000 & 10 \\
U2. Office & $10 \times 10$ & 200 & 300000 & 0.1 \\
$\begin{array}{c}\text { U3. Auxiliary building for } \\
\text { maintenance }\end{array}$ & $10 \times 10$ & 10 & 200000 & 2 \\
\hline U4. Small volume storage tank 1 & $10 \times 10$ & 1 & 100000 & 100 \\
U5. small volume storage tank 2 & $10 \times 10$ & 1 & 100000 & 100 \\
U6. Utility & $10 \times 10$ & 5 & 500000 & 50 \\
\hline DU. Distillation unit & $20 \times 20$ & - & - & - \\
\hline LST. Large volume storage tank & $10 \times 10$ & - & - & - \\
\hline
\end{tabular}

Table 9 Safety distances

\begin{tabular}{ccccc}
\hline Units & $\begin{array}{c}\text { Small Storage } \\
\text { (U4,U5) }\end{array}$ & $\begin{array}{c}\text { Utility building } \\
\text { (U6) }\end{array}$ & $\begin{array}{c}\text { Distillation Unit } \\
\text { (DU) }\end{array}$ & $\begin{array}{c}\text { Large Tank } \\
\text { (LST) }\end{array}$ \\
\hline Main control room(U1) & $30 \mathrm{~m}$ & $30 \mathrm{~m}$ & $50 \mathrm{~m}$ & $76 \mathrm{~m}$ \\
Office(U2) & $15 \mathrm{~m}$ & $30 \mathrm{~m}$ & $50 \mathrm{~m}$ & $76 \mathrm{~m}$ \\
Maintenance building(U3) & $15 \mathrm{~m}$ & $30 \mathrm{~m}$ & $50 \mathrm{~m}$ & $76 \mathrm{~m}$ \\
\hline
\end{tabular}


Table 10 Slices boundaries

\begin{tabular}{cccc}
\hline Slice & $\begin{array}{c}\text { LAs } \\
\text { (degrees) }\end{array}$ & $\begin{array}{c}\text { UAs } \\
\text { (degrees) }\end{array}$ & $\boldsymbol{P} \boldsymbol{f}_{\boldsymbol{s}}$ \\
\hline 1 & 292.5 & 157.5 & 0.1 \\
2 & 157.5 & 180 & 0.15 \\
3 & 180 & 202.5 & 0.15 \\
4 & 202.5 & 247.5 & 0.20 \\
5 & 247.5 & 292.5 & 0.15 \\
\hline
\end{tabular}




\section{CAPTIONS FOR FIGURES}

Figure 1. Graphic representation of a Quantitative Risk Analysis

Figure 2. Non-overlapping possibilities for the placement of unit i with respect to unit j; right, left, above and below

Figure 3. Instantaneous Release Bow tie

Figure 4. Continuous Release Bow tie

Figure 5. Graphical representation of safe distances

Figure 6. Wind rose diagram for case study 1

Figure 7. Optimal layout for case study 1 considering all outcomes

Figure 8. Model solution considering individual outcomes

Figure 9. Additional results for case study 1. (a) Contributions to the objective function considering individual and all outcomes. (b) Area-societal risk tradeoff

Figure 10. Optimal layout obtained for case study 2 


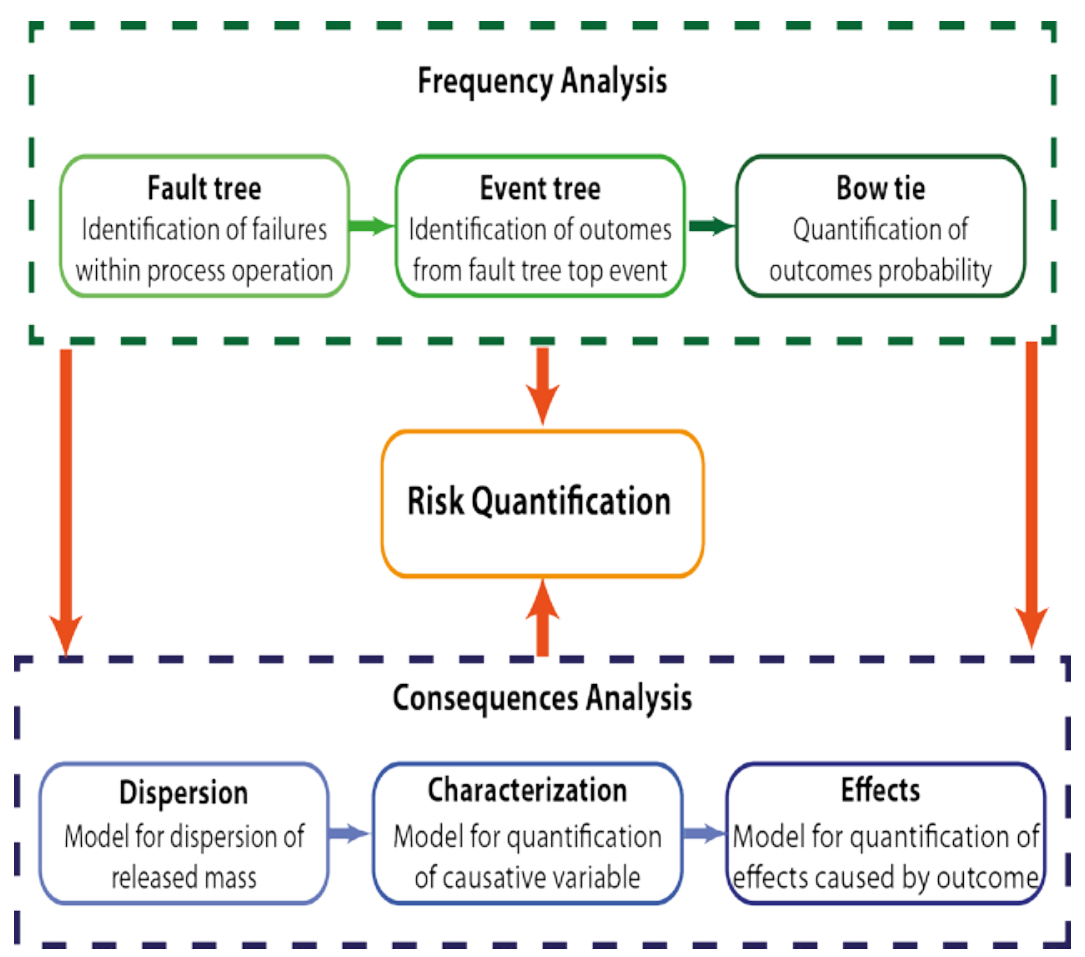

Figure 1 


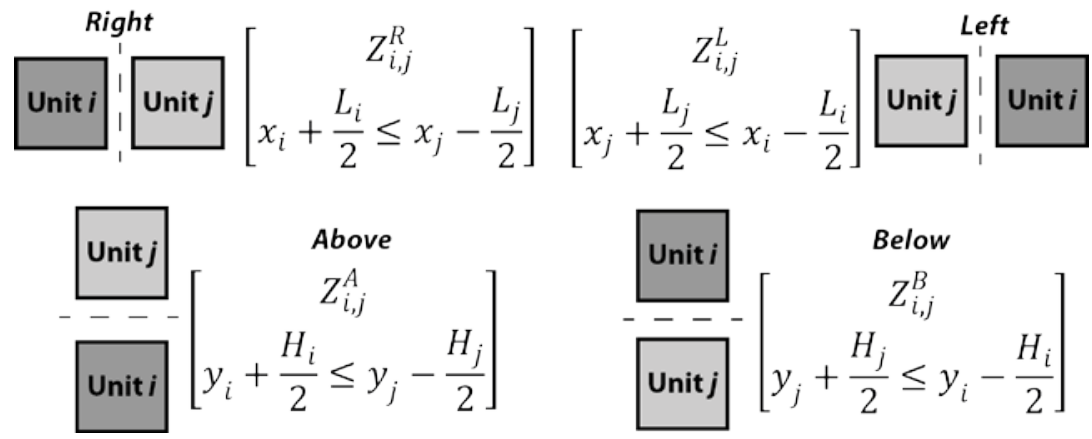

Figure 2 


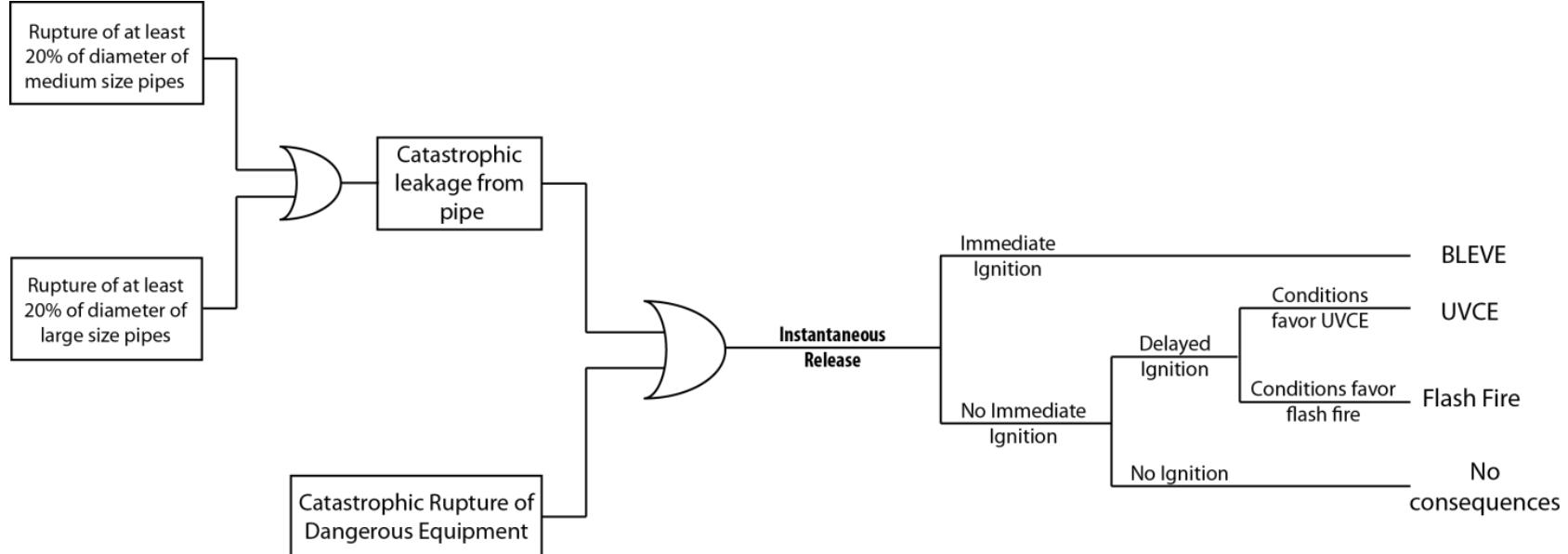

Figure 3 


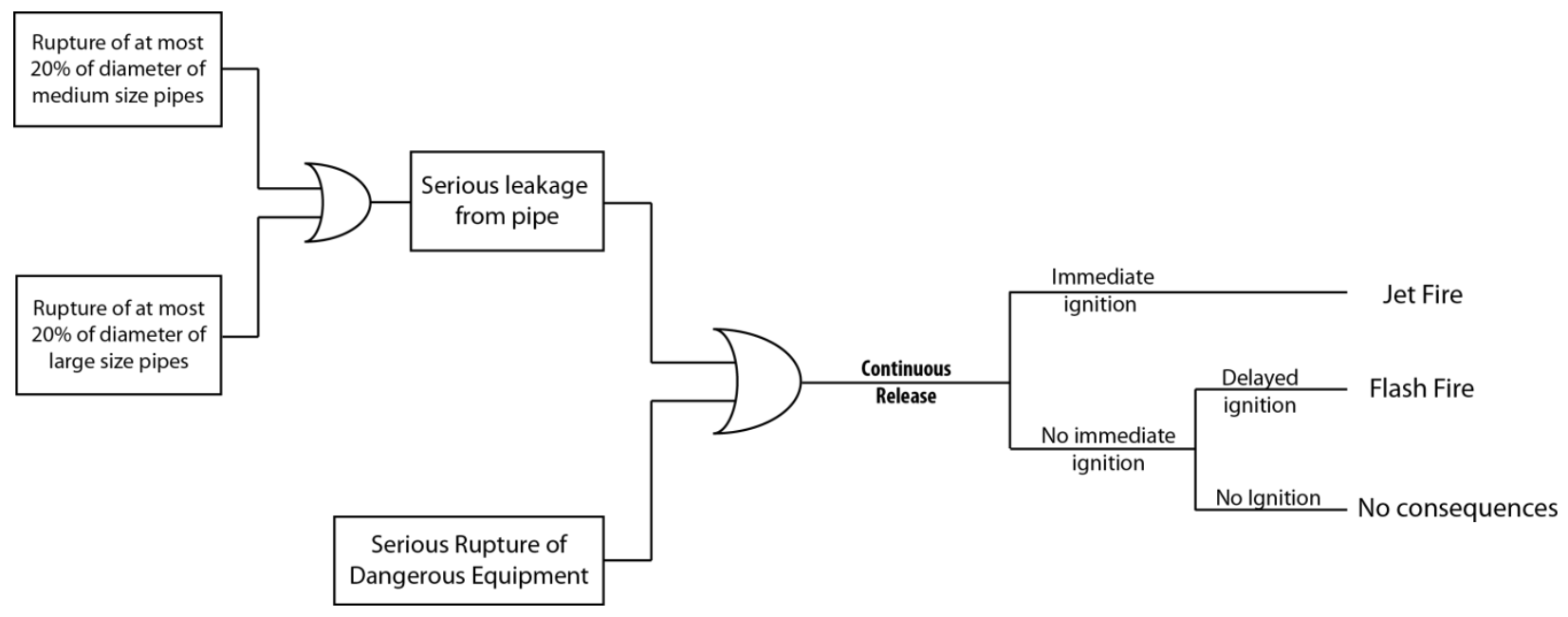

Figure 4 


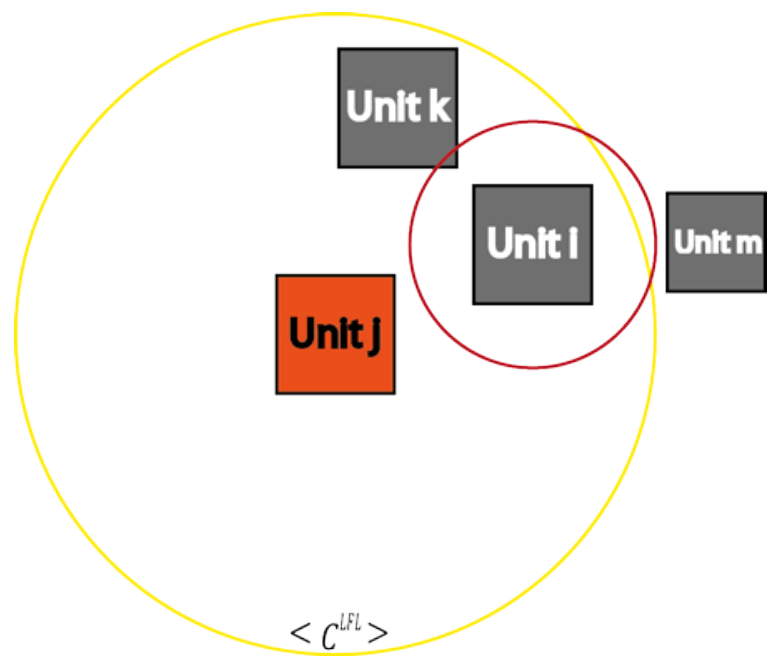

Figure 5 


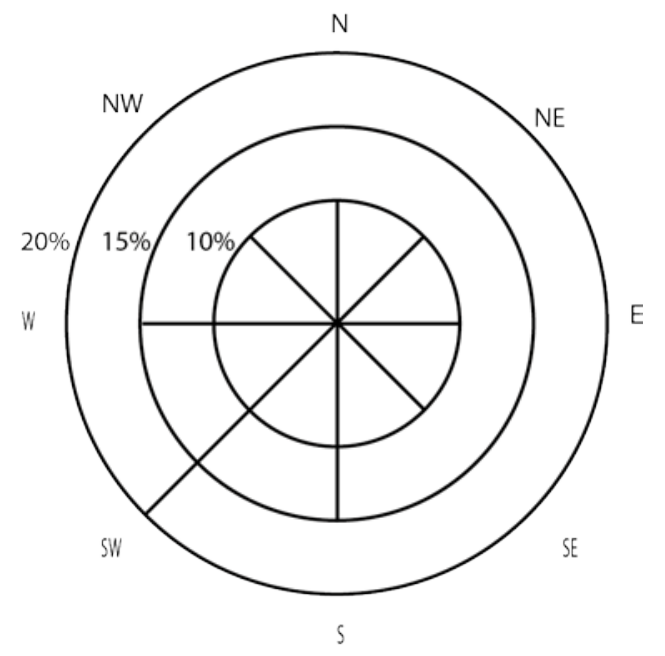

Figure 6 


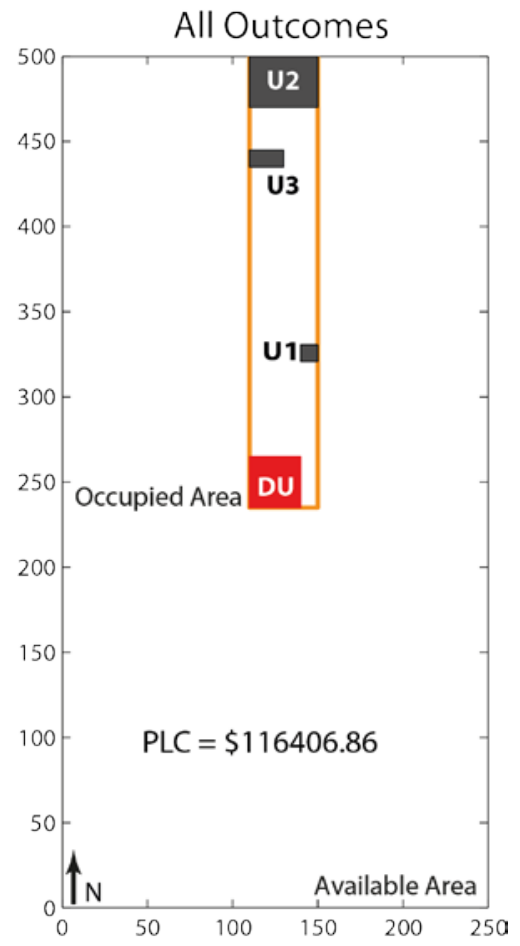

Figure 7 

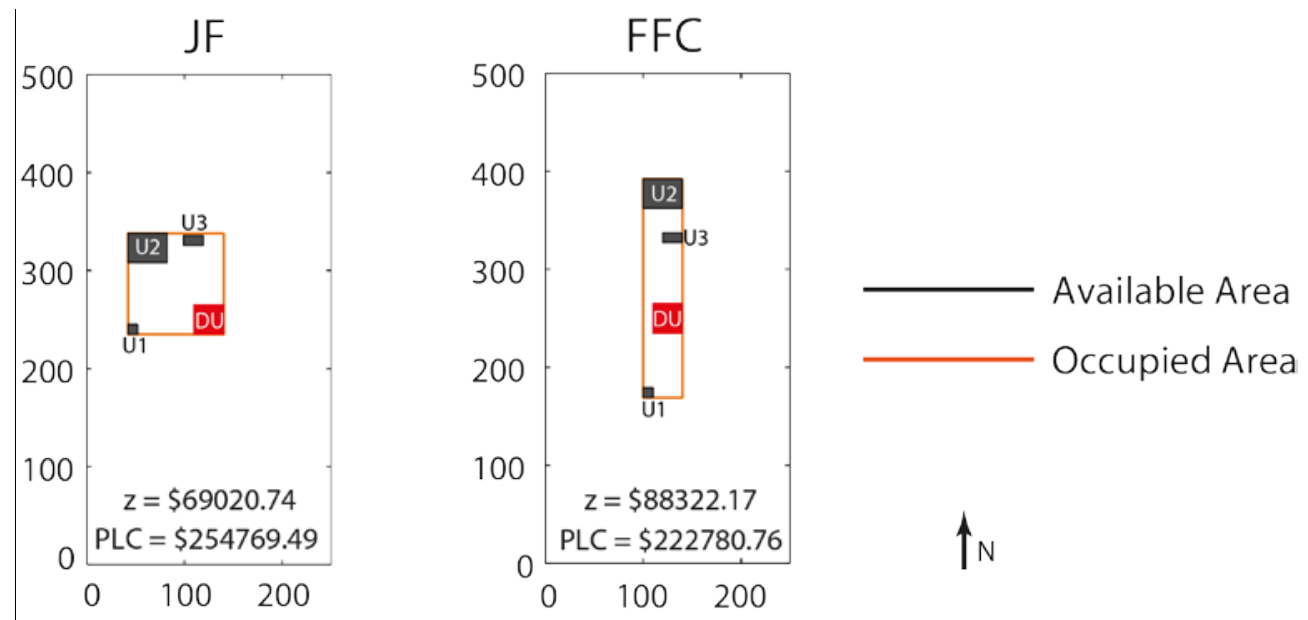

BLEVE

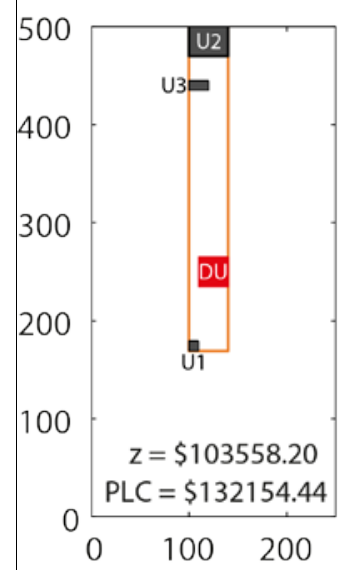

UVCE

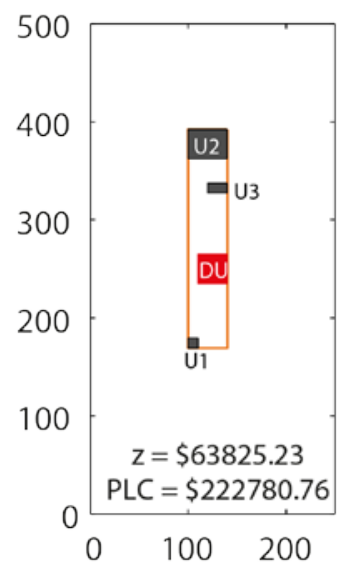

FFI

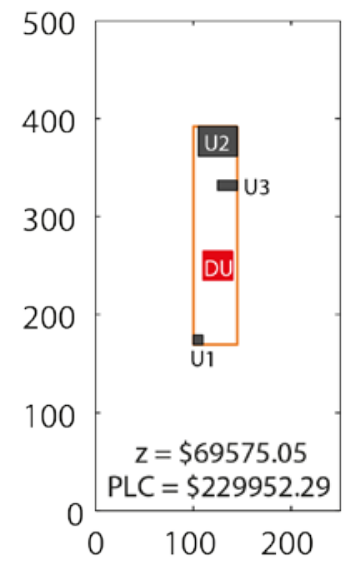

Figure 8 
(a)

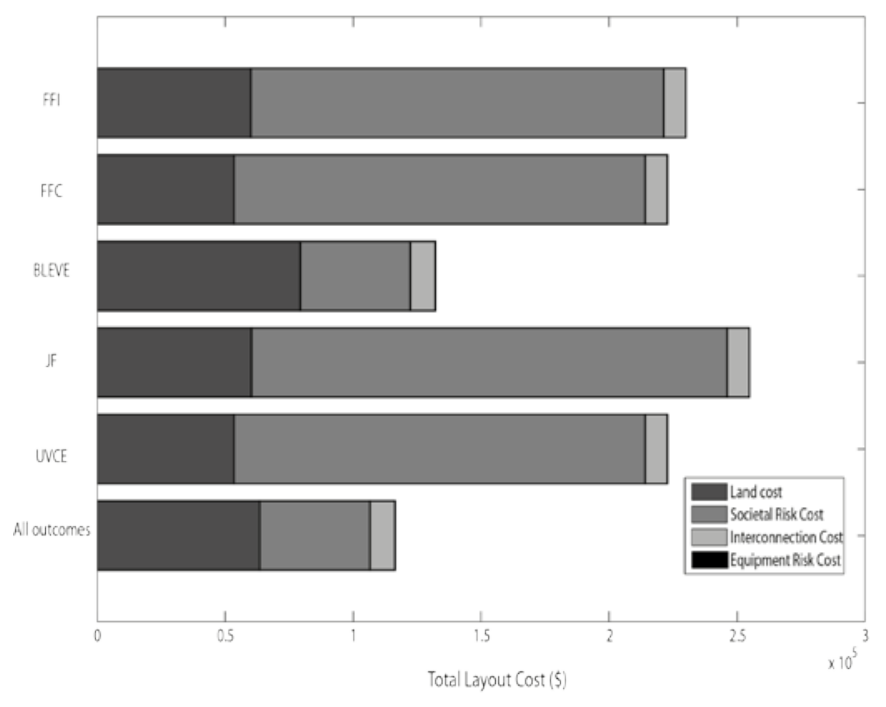

(b)

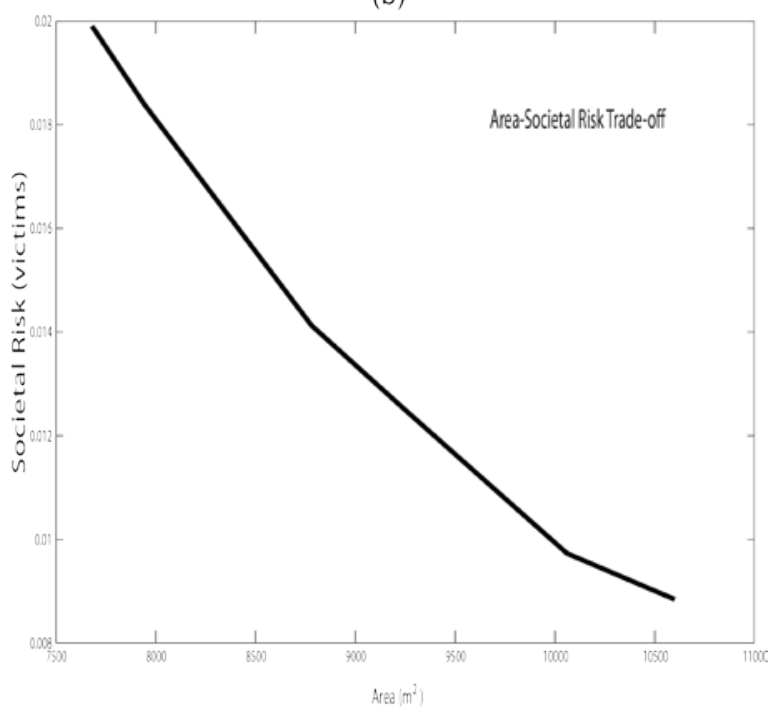

Figure 9 


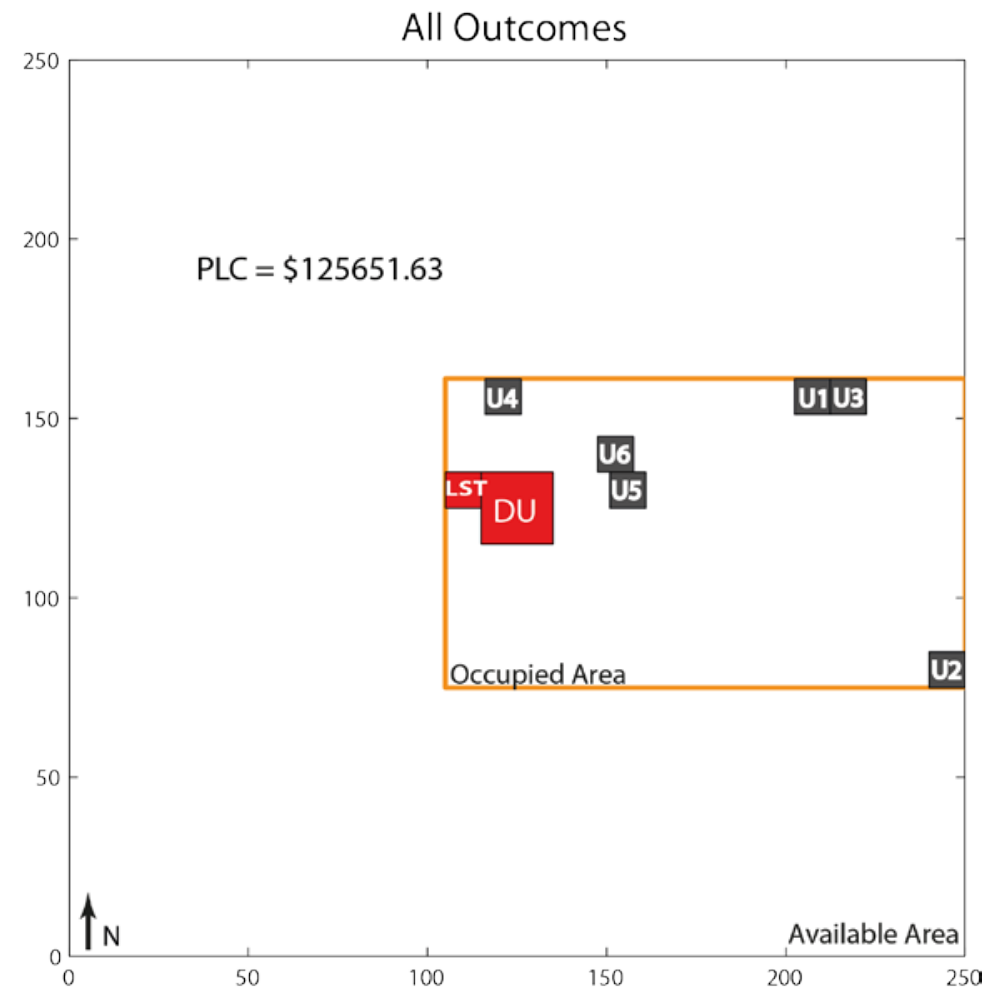

Figure 10 